\title{
La utilidad de los modelos matemáticos para los procesos de enseñanza de la tecnología
}

\author{
The utility of mathematical patterns for the processes about teaching of \\ technology
}

Hernán Santiago Nottoli

\author{
Profesor Titular Consulto, Centro de Matemática y Diseño, Facultad de Arquitectura, Diseño y \\ Urbanismo, Universidad de Buenos Aires, Buenos Aires - Argentina \\ nacho_nottoli@yahoo.com.ar
}

\section{RESUMEN}

El profundo cambio originado por el avance de la microelectrónica, es una realidad que ya se encuentra entre nosotros. En la Arquitectura y en la Ingeniería, los sistemas gráficos interactivos y dinámicos son de uso generalizado e incluso comprenden los aspectos gráficos de la Matemática. En consecuencia, se desea destacar la estrecha participación de los modelos matemáticos en los procesos de enseñanza de la tecnología en la educación arquitectónica.

Hoy existen nuevos conceptos que se han gestado en los últimos tiempos y entre los renovadores campos matemáticos que se usan al diseñar: se destacan: la geometría fractal, los espacios multidimensionales, los mosaicos no periódicos; las superficies mínimas. Hoy no es posible diseñar y manejar conceptos estructurales de alta complejidad, sin el uso de modelos matemáticos y ello es lo que se propone enfatizar en este trabajo, acompañando las ideas centrales con algunos ejemplos de obras de arquitectura de reconocido valor en el campo internacional.

\section{ABSTRACT}

The great change originated by the advance of microelectronics is a reality that has already taken place among us. Within Architecture and Engineering the interactive and dynamic graphic systems have a generalized use, and also cover the graphic aspects of Mathematics. Consequently, what will be here enphasized is the close participation of mathematical patterns in the processes of teaching of building technology in architectural education.

Now a days there are new concepts recently originated, among these renovating mathematical fields, that are used to design should be highlighted fractal geometry, multidimensional spaces, minimum surfaces. Today it is not possible to design or to handle stuctural concepts of high complexity without the support of mathematical patterns; which is precisely what this presentation sets out to emphasize accompanying the central ideas with architectural examples of buildings that deserve international recognition.

PALABRAS CLAVES: Modelos matemáticos, Geometría, Diseño, Enseñanza, Pedagogia.

KEY WORDS: Mathematical patterns, Geometry, Design, Teaching, Pedagogy.

FECHA DE RECEPCIÓN: 20/8/2021| FECHA DE ACEPTACIÓN: 22/10/2021

DOI: http://dx.doi.org/10.30972/arq.0185668 


\section{LA RELACIÓN DE LA TECNOLOGÍA CON LA MATEMÁTICA}

El mundo visual está basado en dos experiencias: que la gravedad es vertical y que el horizonte forma un ángulo recto con ella. La imagen vertical plana surge de la cuádruple rotación sobre sí mismo del ángulo recto, al igual que la imagen horizontal plana surge del mismo procedimiento relativo a los cuatro puntos cardinales. Esta geometría de las primeras culturas que estuvo al servicio de la agrimensura y la astronomía, también lo estuvo al servicio de la edificación y con Euclides, por primera vez, el método lógico deductivo estructura una geometría propiamente matemática.

Hoy, como fue dicho en el resumen de este trabajo, ya se han incorporado al campo del diseño temas como la geometría fractal, que sirve de modelo para variadas expresiones del campo proyectual, desde lo urbano hasta la generación de utensilios de uso cotidiano del hombre; los espacios multidimensionales, que ya tienen variados ejemplos arquitectónicos construidos; un ejemplo es el Arca de la Defensa de París, que es un hipercubo tetradimensional.

La relación de la tecnología con la matemática, en especial la rama geométrica, resulta evidente por su campo de acción en el espacio. La geometría es la disciplina matemática que se ha caracterizado por la elaboración de modelos matemáticos capaces de describir parcelas concretas del espacio, por lo que cabe considerar que el espacio geométrico resulta una aportación teórica, clara y sugerente, al estudio de ciertas facetas del espacio arquitectónico.

Un trazado axonométrico de un objeto tridimensional es un modelo geométrico y a la vez un modelo arquitectónico, dándose en ambos casos la característica de que el objeto real no tiene porque existir todavía.

La geometría proyectiva del renacimiento, con sus secciones, proyecciones y representaciones; la geometría analítica de Descartes que entrelaza las posibilidades del lenguaje euclídeo con las posibilidades algebraicas de las ecuaciones y la aritmética; la geometría descriptiva de Monge con sus técnicas de expresión gráfica y la que en la actualidad, mediante las posibilidades de los ordenadores se conoce como geometría fractal, conforman un lenguaje que en no pocas ocasiones constituye la ineludible manera de expresarse del arquitecto y el ingeniero. Este lenguaje, tanto en el plano como en el espacio, está formado por elementos o entidades comunes susceptibles de ser combinados para crear o transformar dicho espacio; y su conocimiento y dominio son necesarios para el diseño y la tecnología constructiva.

Por su parte, el uso de los ordenadores, en especial de aquellos destinados al procesamiento de imágenes, se ha constituido en una valiosa herramienta para el desarrollo e investigación de los conocimientos precedentes y a la vez un punto de partida para nuevas conceptualizaciones. No es necesario, para un usuario de un sistema gráfico interactivo, conocer la estructura matemática que hace posible su funcionamiento, tan sólo debe saber su manejo y en qué debe aplicarlo. Sí, es sumamente necesario que conozca los elementos o entidades que puede manejar y qué atributos les puede asignar.

Es aquí, donde se produce una notoria simbiosis entre los conocimientos de la matemática, el uso de los ordenadores y la arquitectura. Luego habrá que transferir todos estos conocimientos a la tecnología constructiva para un correcto manejo del espacio arquitectónico, sus técnicas constructivas, el cálculo estructural de los elementos que lo componen, elementos que deben formar parte del bagaje de los estudiantes y profesionales de la arquitectura.

El manejo del espacio tridimensional, notoriamente potenciado por los sistemas CAD -3D (tres dimensiones), con sus variantes de tratamiento de superficies y sólidos se apoya, en su totalidad, en los conocimientos matemáticos tradicionales, por lo que su dominio depende de las transformaciones posibles de las coordenadas correspondientes y sus consecuentes entidades. 
No obstante hay un aspecto particular que es necesario señalar. Es el que se refiere al hecho de que los dispositivos de diálogo en los sistemas interactivos, son las pantallas de los ordenadores y que éstas muestran una superficie de dos dimensiones, aún en los casos en que se esté trabajando en tres dimensiones. Por lo tanto es sumamente necesaria una adecuada ejercitación en la educación arquitectónica que contemple, por un lado los aspectos de percepción espacial de los estudiantes y por el otro, la provisión de las herramientas necesarias de tipo tecnológico y conceptual de cálculo que lleven sus ideas a posibilidades concretas de ejecución.

Considerando que cada día es mayor la cantidad de alumnos que conocen el manejo de los ordenadores pero que ignoran sus aplicaciones en la arquitectura, en los aspectos gráficos se debe insistir en incorporar como temática esta disciplina. No es que se defienda específicamente la enseñanza del uso de los ordenadores para dibujar (ello será atributo de cursos específicos de $C A D$ ), tan sólo se trata de poner énfasis en aquellos conocimientos de la matemática que deberán ser aplicados para su correcta utilización.

También debe considerarse como objetivo de la educación arquitectónica, buscar la síntesis como un mecanismo deseado y procurar que los conocimientos resulten de evidente aplicación en la actividad principal, que es el diseño y es esencialmente heurística.

\section{OBJETIVOS}

En todo proceso enseñanza-aprendizaje hay aspectos psicológicos que hacen a la eficiencia del sistema adoptado. Uno de los principales es lograr la participación activa del alumno para lo cual es necesario interesarlo previamente.

La motivación previa debe estar basada en la necesidad y utilidad del conocimiento a transmitir, mientras que la participación activa es posible mediante propuestas que impliquen un análisis y una deducción para de este modo avanzar en el conocimiento. Este mecanismo proporciona una formación adecuada para enfrentar nuevas situaciones.

Se proponen como objetivos básicos de los procesos de la educación arquitectónica:

- Eliminar el divorcio entre la clase teórica y la aplicada. Que los docentes logren un mejor conocimiento del alumno y que éste puede participar en forma activa y no como un receptor de una clase magistral. Limitar la clase de exposición al aspecto conceptual, incentivando al alumno a que utilice material didáctico.

- Proporcionar material didáctico pertinente a la temática abordada por los cursos. Brindar una adecuada bibliografía actualizada y la metodología para acceder a nuevos materiales, dada la permanente y vertiginosa transformación que sufren los sistemas tecnológicos en todas sus ramas.

- Requerir a los alumnos aplicaciones de los conocimientos obtenidos mediante trabajos que deben ser concebidos y desarrollados por ellos mismos y que en la medida de lo posible respondan a requerimientos multidisciplinares del diseño.

- Dotar a los cursos de evaluaciones (parciales y total), buscando alcanzar altos grados de conceptualización de los conocimientos impartidos, así como también una aprehensión de las herramientas más adecuadas para la labor profesional vinculada a la temática impartida en las clases.

- Utilizar los recursos didácticos-informáticos disponibles para lograr una mejor ejemplificación de los conceptos impartidos. Asimismo, propiciar que los alumnos deban abocarse a plantear y solucionar problemas no convencionales, que se resuelvan más con inventiva que con algoritmos clásicos, despertando el aspecto heurístico que acompaña instrumentalmente al acto de creación. 
Como ejemplos de los conceptos antes citados en este trabajo, se muestran a continuación un par de casos de obras de arquitectura, de compleja tecnología constructiva, donde es posible verificar el uso directo de componentes matemático-geométricos, informáticos y gráficos que se relacionan en forma directa con el acto de diseñar.

El primer ejemplo es el complejo edilicio de las llamadas Torres Petronas (Figura 1) de Kuala Lumpur, capital de Malasia, obra del Arq. Pelli ${ }^{1}$ una de las obras más destacadas del siglo XX por su trascendencia internacional como edificio símbolo. Su significación, y el uso claro y manifiesto de la matemática en su diseño básico, le valieron ganar el concurso convocado para ese edificio.

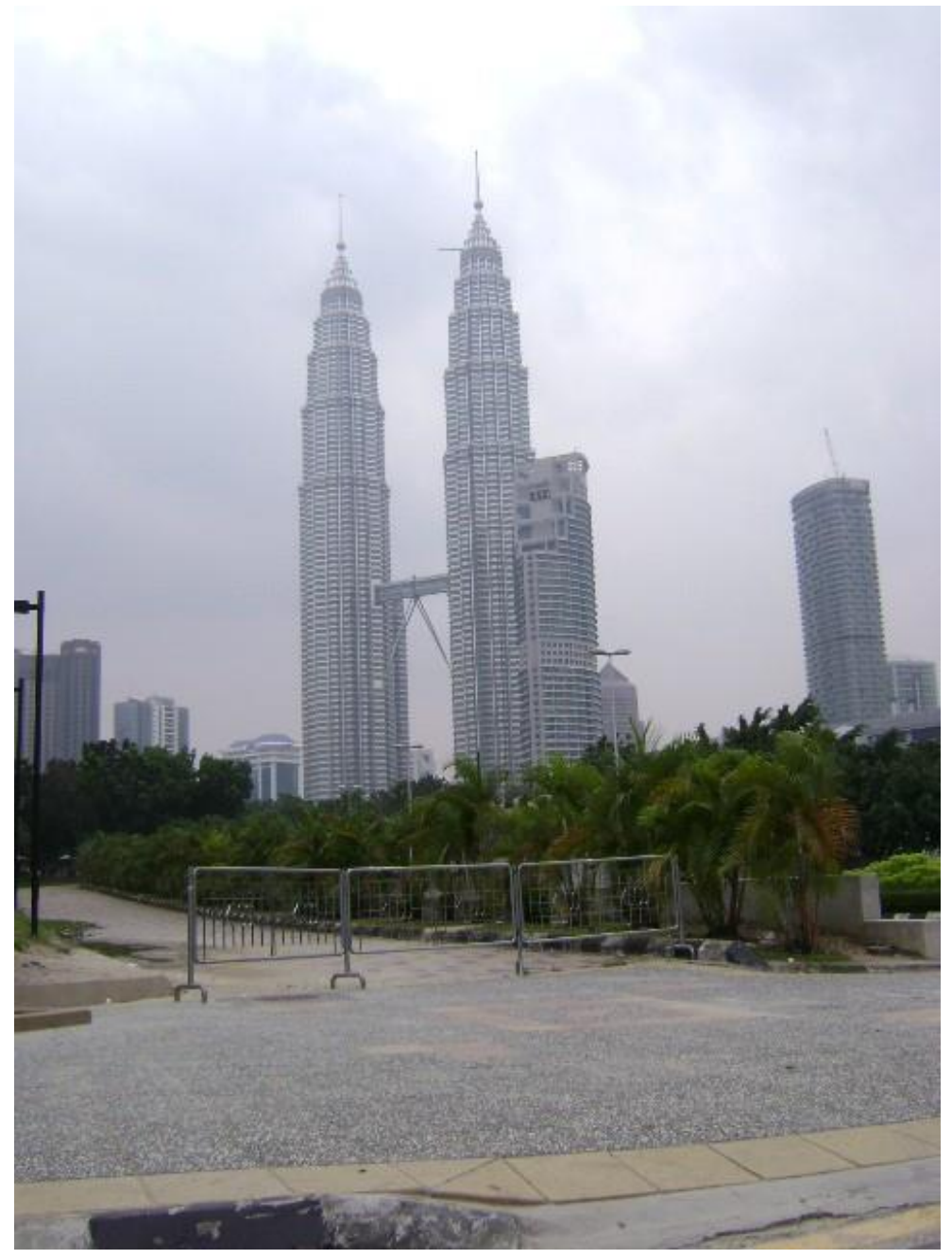

Figura 1 Torres Petronas

Fotografía del autor

Con sus 452 metros de altura, el diseñador le impuso una impronta islámica, lograda entre otros recursos, con una planta concebida con un modelo matemático basado en la intersección de dos cuadrados de baricentro coincidente, que conforman así una estrella virtual de 8 puntas, donde los círculos que le terminan de definir el perímetro, producen esa imagen de templo arabesco que identifica la cultura del pueblo que la erigió (Figuras 2 a y b). 

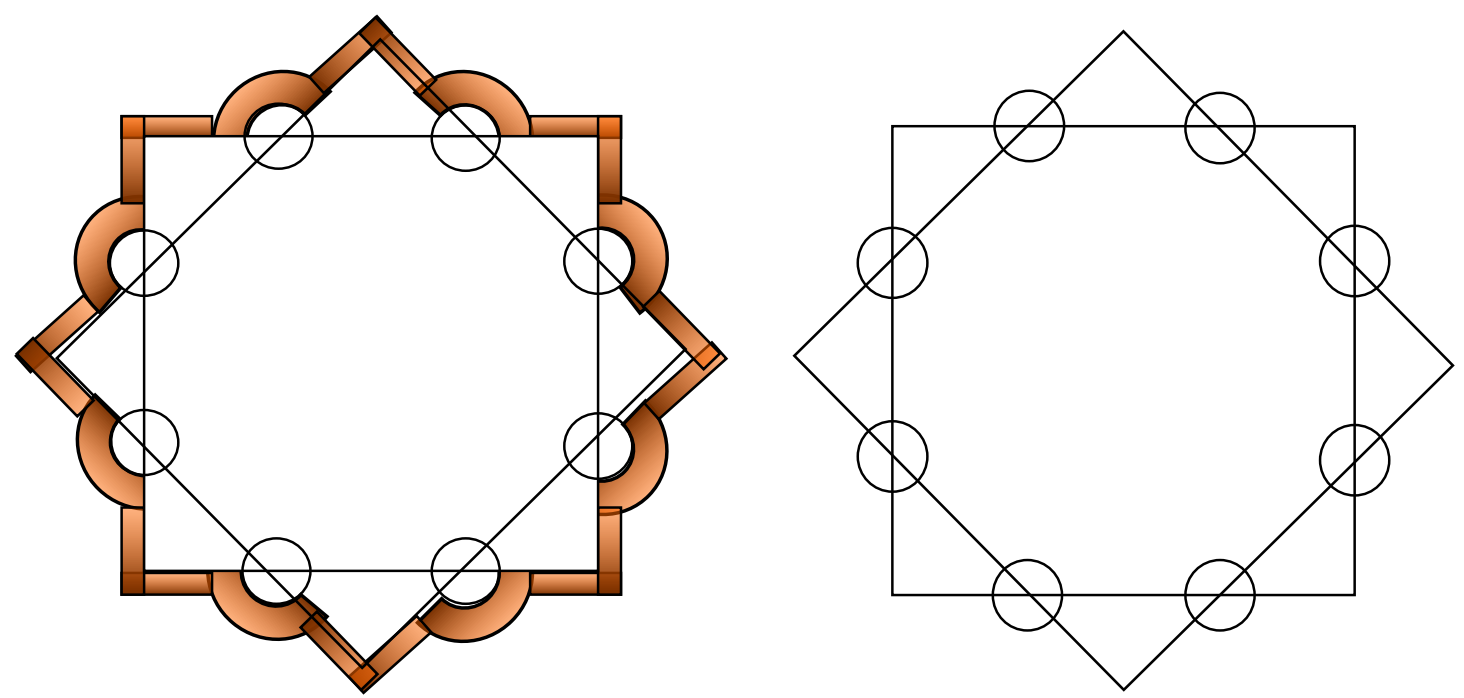

Perímetro de la planta de las Torres Petronas de Kuala Lumpur y su esquema geométrico de generación.

Figuras 2 a y b

Diseño del autor

El segundo ejemplo es el templo de la Sagrada Familia (Figuras 3 y 4) de la Ciudad de Barcelona, España, obra del célebre Arq. Gaudí ${ }^{2}$, que trabajó todas sus obras imponiéndoles sofisticados e ingeniosos recursos matemáticos, totalmente asociados a la tecnología constructiva en diseño arquitectónico.

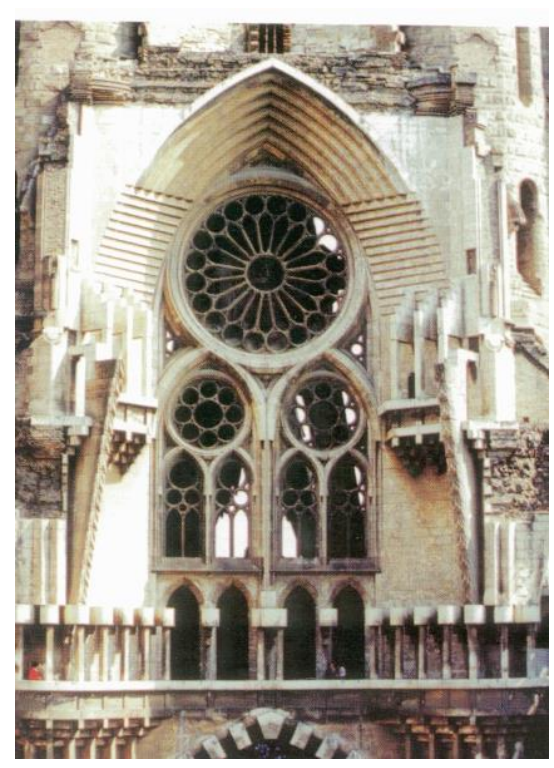

Figura 3 Templo Sagrada Familia

Fotografía del autor

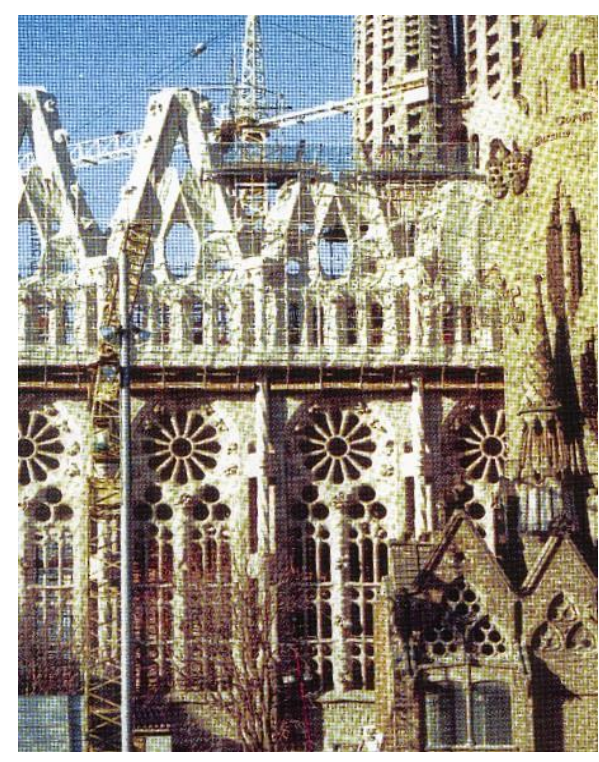

Figura 4 Templo Sagrada Familia

Fotografía del autor

Si bien este afamado arquitecto trabajó en la definición de sus espacios habitualmente con cuádricas regladas y conoides, que permiten su ejecución técnica con encofrados de módulos 
lineales - aunque Gaudí nunca construyó ni pensó sus obras para ser realizadas en hormigón armado - también concibió sus obras con otras superficies cuádricas tales como paraboloides de revolución y elipsoides, que utilizó de forma más puntual, sobre todo en los nudos y en los capiteles de columnas y techos de varias de sus concepciones más audaces.

Es destacable señalar que Gaudí estaba totalmente familiarizado con estas superficies no planas en espacios tridimensionales, conocimientos que sin dudas adquirió en su paso por la Escuela de Arquitectura de Barcelona, ciudad en la que desarrolló la mayoría de sus proyectos - hay muy pocos fuera del ámbito de esta región española - y gracias al invalorable apoyo de un mecenas como lo fue el magnate Güell.

Este hombre de gran poder económico fue quien le encomendó las más significativas de sus obras, entre las que se cuentan las caballerizas de la Finca Güell; el Palau Güell (casa del mecenas en el centro de la ciudad de Barcelona); el famoso Parc Güell, en el que se pueden admirar numerosos alardes de diseño con componentes geométricos sofisticados de todo tipo, obras todas ellas en las que Gaudí usó en cúpulas y capiteles el hiperboloide de revolución.

El templo de la Sagrada Familia, del cual se mostrarán a continuación algunas imágenes demostrativas, es la obra cumbre de Gaudí, donde el hiperboloide de una hoja constituye una pieza fundamental de los techos de las naves.

En la solución de esos techos es posible observar que los capiteles de las columnas que soportan los esfuerzos de esa cubierta están conformados por medio hiperboloide pleno que permite la continuidad con la sección circular de la parte superior de las columnas. Para la conformación de esa techumbre, también el arquitecto recurrió al hiperboloide, pero virtual, es decir conformado solo por su piel, formando así un conjunto de claraboyas soportadas por las columnas, por donde ingresa la luz natural que ingresa por los planos superiores, asociada a la luz artificial que se instala en los mismos espacios para producir un efecto similar en horas nocturnas. Las superficies de estos hiperboloides de una hoja están tratadas con texturas que muy al estilo gaudiano, generan efectos cromáticos agregando originalidad y singularidad a las formas y al paso de la luz rozando dichas superficies.

Es indudable que los ordenadores - que hoy se usan para generar las piezas que van completando el templo de la Sagrada Familia - inexistentes en los tiempos de vida de Gaudí, resuelven en la actualidad una serie de procedimientos que el arquitecto debió crear y solucionar con metodologías más ingeniosas, tales como modelos de yeso, planos de luz a través de hendijas que "atravesaban" maquetas de hilos, y los bastante conocidos modelos de poligonales conformadas por hilos que sostienen pesas y que constituyen funiculares solicitados a la tracción. Gaudí invertía esas imágenes luego por medio de espejos, para generar sus superficies trabajando a la compresión, totalmente compatibles con las características resistentes de los materiales básicos que usaba en sus obras, es decir: la piedra y el ladrillo.

Otra superficie también reglada y usada por Gaudí fue la de paraboloides hiperbólicos que este arquitecto usó para resolver el paso de un hiperboloide de una hoja a otro, incorporando también lóbulos parabólicos y planos diédricos como solución de encuentro de superficies cuádricas.

Se muestran a continuación algunos gráficos relativos a superficies cuádricas presentes en el Templo de la Sagrada Familia de Barcelona, indicando una secuencia que permite apreciar en este caso la obtención de dichas superficies mediante el proceso llamado "operaciones booleanas de sustracción", que consisten en general en la unión, intersección o diferencia entre dos o más figuras sólidas (Figuras $5,6,7,8,9,10$, y 11) ${ }^{3}$. 


\section{8}

La utilidad de los modelos matemáticos para los procesos de enseñanza de la tecnología
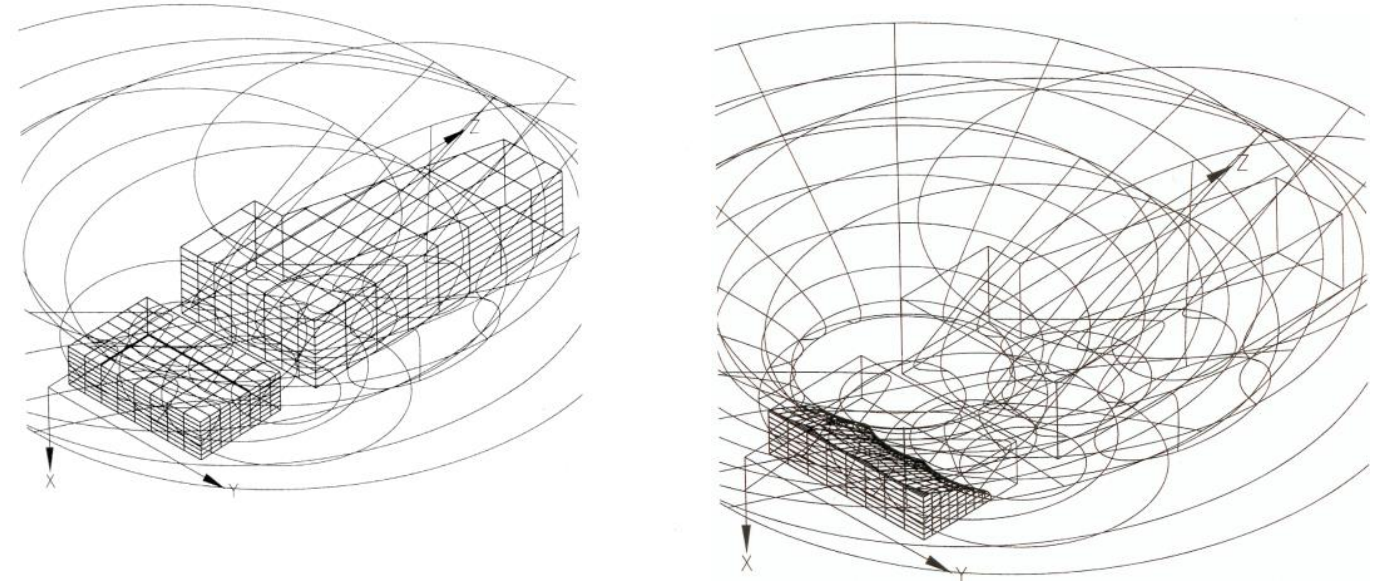

Figura 5

Figura 6
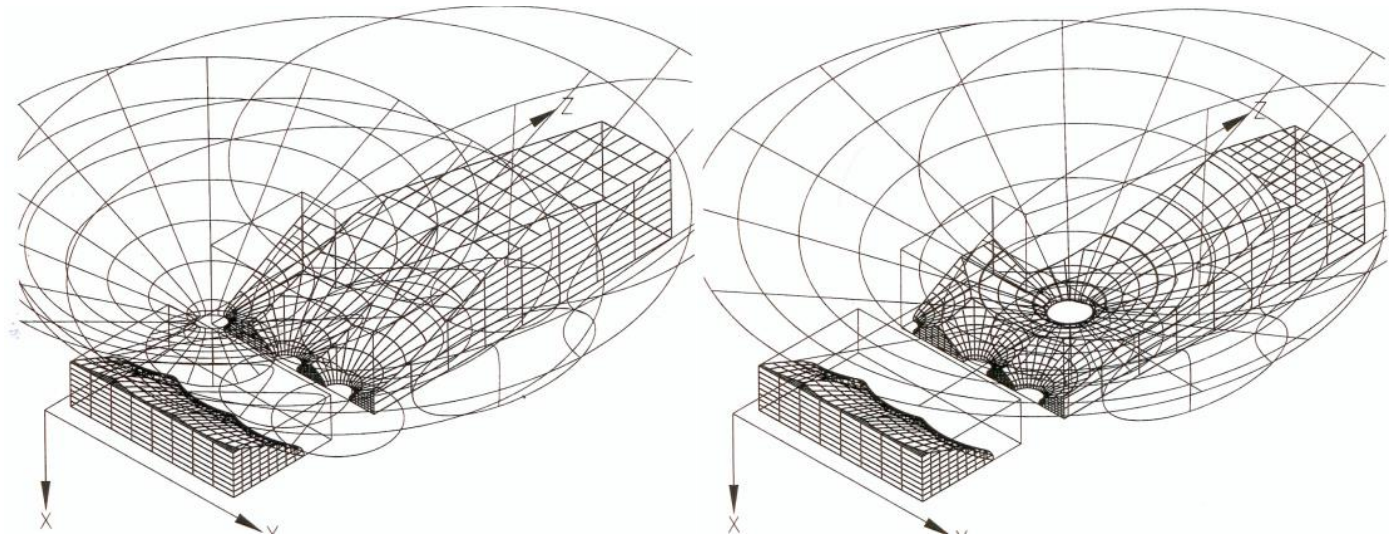

Figura 7

Figura 8 


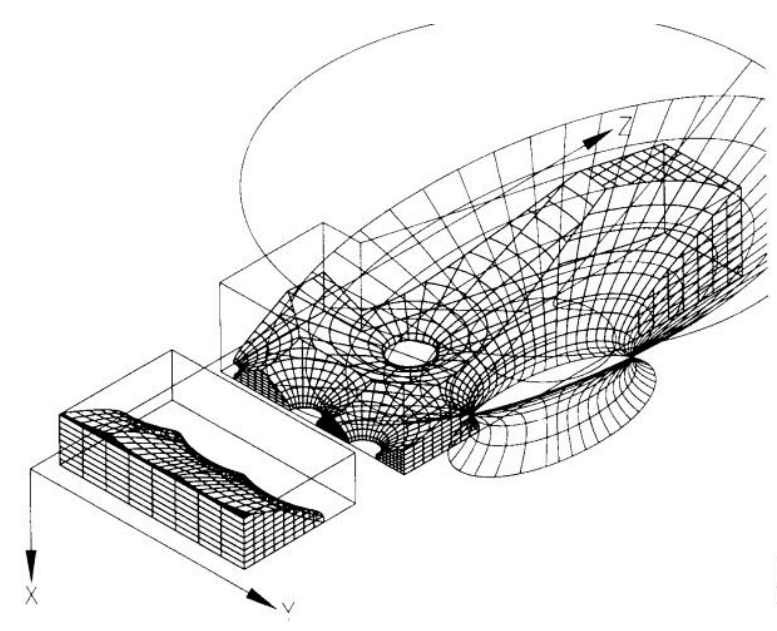

Figura 9

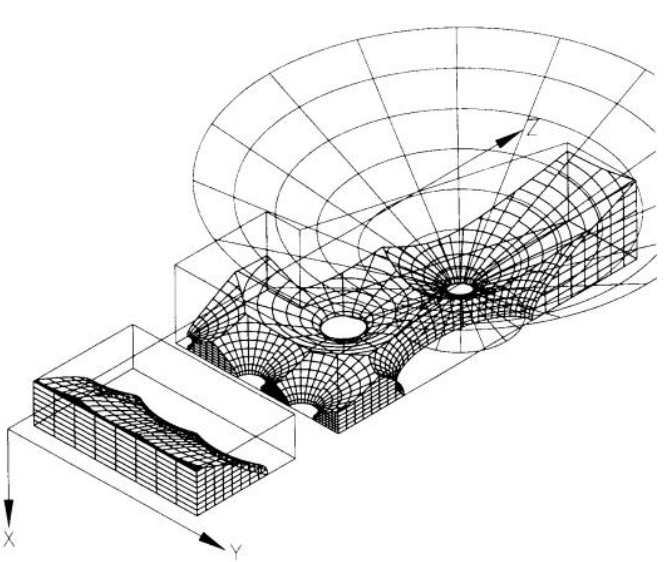

Figura 10

En las imágenes anteriores es posible percibir, si se observan en detalle, que a partir del módulo prismático inicial, se le van sustrayendo (cortando valdría decir ya que en la realidad ese es el trabajo que se hace en la pieza pétrea) sucesivas porciones que poseen la forma de hiperboloides de una hoja 4 .

Finalmente se obtiene el siguiente modelo tridimensional, que constituye uno de los módulos que aparecen en las fachadas, los remates de capiteles y parte de los frontis de la Iglesia de la Sagrada Familia de Barcelona.

\section{COLOFON}

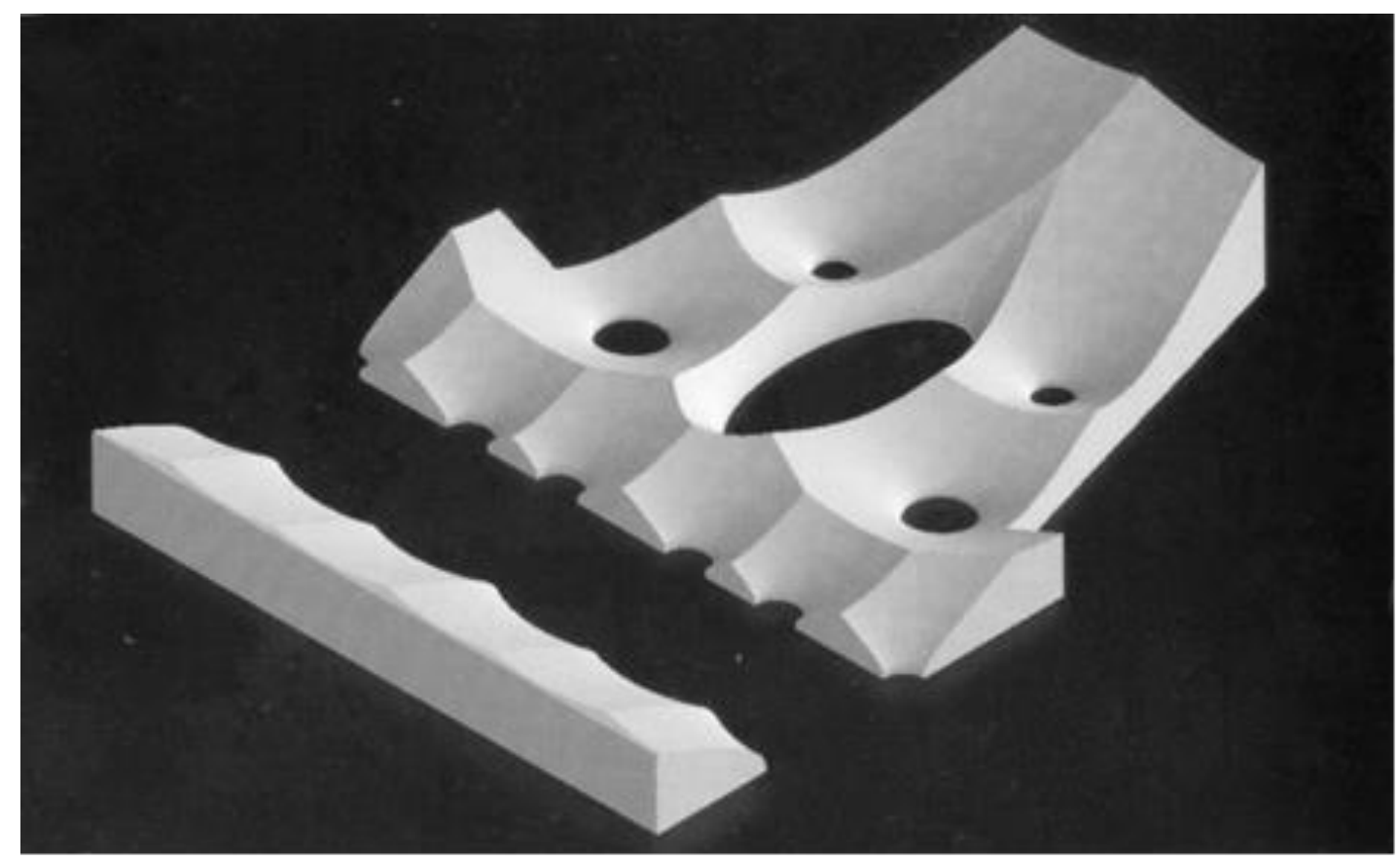

Figura 11

Como puede desprenderse de los ejemplos antes desarrollados, hoy puede decirse sin ambages que los estudiantes de arquitectura y diseño deben poseer más que nunca, acendrados y 
profundos conocimientos tecnológicos para ser luego eficientes profesionales. Ser conscientes de este problema es el primer paso para un educador.

Desafortunadamente, los actuales niveles de los colegios preuniversitarios de muchas partes del mundo, de países desarrollados y mucho más en subdesarrollados, están pautados de forma tal que no facilitan en los estudiantes el ejercicio de sus capacidades de raciocinio.

Si se despierta el interés de los alumnos en la tecnología constructiva del diseño arquitectónico, ello sin dudas redundará en un acrecentamiento de su capacidad de razonamiento. Por lo tanto, es esencial generar profundos y sólidos conocimientos tecnológicos prácticos y teóricos, simultáneamente con la enseñanza de la capacidad de utilización y aplicación que tienen esas áreas del saber en todos los órdenes de la vida contemporánea, incluido por supuesto el proceso de diseñar. Es de esa manera que los estudiantes podrán acercarse más a la tecnología constructiva, percibir su utilidad, sentir el placer de transitar por sus apasionantes laberintos y desarrollar a partir de ello su propia capacidad intelectual y creativa.

\section{REFERENCIAS}

1.- Pelli, César, recientemente fallecido, fue un arquitecto argentino que estudió en la Universidad nacional de Tucumán una pequeña provincia de su país y que creó uno de los estudios de arquitectura más grande y prestigioso del mundo con sede en la ciudad de Nueva York, EEUU. Datos mnemotécnicos del autor obtenidos en su trayectoria académica universitaria y artículos periodísticos del obituario del profesional referido.

2.- Gaudí, Antoni, arquitecto que desarrolló su labor en la región de Cataluña, España desde fines del siglo XIX hasta inicios del siglo XX y que se destacó por sus originales diseños donde predominan las superficies curvas y el uso de una tecnología constructiva asociada directamente a la morfología del diseño. Datos mnemotécnicos del autor obtenidos en su trayectoria académica universitaria.

3.- La secuencia gráfica de las figuras 5 a 11 pertenecen a un modelo del libro "La Sagrada Familia de Gaudí al CAD" de la Editorial de la Universitat Politécnica de Catalunya, 2008.

4.- El hiperboloide de una hoja es una superficie que se genera haciendo girar una hipérbola alrededor de un eje exterior a su parte convexa. Los ejemplos clásicos de este tipo de forma son los cestos para papeles de alambre o las torres de evaporación de las centrales nucleares.

\section{BIBLIOGRAFÍA}

Gómez, Josep; Coll, Jordi; Melero, Juan C.; Burry, Mark C. (2008). La Sagrada Familia de Gaudí al CAD. Publicado por Edicions Upc - ISBN: 9788483019184 . Barcelona, España.

Nottoli, Hernán. (2017) Libro Enseñanza de matemática para arquitectos y diseñadores, publicado por Ediciones Diseño Editorial. ISBN 978-987-4000-88-0. 308p. Buenos Aires, Argentina.

Nottoli, Hernán. (2021) Paper aceptado sobre enseñanza en áreas de tecnología, titulado "On teaching in technological area subjects", para su inclusión en la Editoral Academic Star Publishing Company, con sede en Brooklyn, NY, EE.UU. № de Registro: ISSN 2333-25.

Nottoli, Hernán. (2021) Libro Topología aplicaciones a la arquitectura y el diseño publicado por Editorial Nobuko. ISBN 978-1-64360-508-1 - ISBN EBOOK 978-1-64360-509-8. Buenos Aires, Argentina. 
